\title{
Helicobacter pylori Infection and its Potential Association with Idiopathic Hypercalciuric Urolithiasis in Pediatric Patients
}

\section{Ali $\mathrm{AM}^{*}$, Abdelaziz SS ${ }^{2}$ and Elkhatib WF $\mathrm{WF}^{3,4}$}

${ }^{1}$ Department of Pediatrics, International Islamic Center for Population Studies and Research, Faculty of Medicine, Al-Azhar University, Cairo, Egypt

${ }^{2}$ Department of Urology, Faculty of Medicine, Al-Azhar University, Cairo, Egypt

${ }^{3}$ Department of Microbiology \& Immunology, Faculty of Pharmacy, Ain Shams University, African Union

Organization St. Abbassia, Cairo, Egypt

${ }^{4}$ Department of Pharmacy Practice, School of Pharmacy, Hampton University, Kittrell Hall Hampton, Virginia, USA

"Corresponding author: Ali AM, Department of Pediatrics, Faculty of Medicine, Al-Azhar University, Cairo, Egypt, Postal Code: 31991, Dr. Noor Mohammad Khan General Hospital, Fax: +966713221417, Tel: +966556847829, E-mail: abdelrazak_ali@yahoo.com

Citation: Ali AM, Abdelaziz SS, Elkhatib WF (2014) Helicobacter pylori Infection and its Potential Association with Idiopathic Hypercalciuric Urolithiasis in Pediatric Patients. J Immunol Infect Dis 2(2): 202. doi: 10.15744/2394-6512.1.203

Received Date: September 24, 2014 Accepted Date: January 05, 2015 Published Date: January 09, 2015

\begin{abstract}
Objectives: To evaluate the role of Helicobacter pylori infection in the pathogenesis of idiopathic hypercalciuric urolithiasis.

Design \& Setting: Randomized longitudinal controlled study was carried out at Al-Azhar University Hospitals in Cairo and Dommiat, Egypt as well as at Noor Khan General Hospital in Hafer Al-Baten, Saudi Arabia.

Participants: A total of 150 patients categorized into 100 cases (urolithiasis-positive) with urinary stone disease, aged from 5 to 18 years, and met the characteristics of idiopathic urolithiasis in children as well as 50 controls (urolithiasis-negative) that had relatively similar demographic criteria except for idiopathic urolithiasis.
\end{abstract}

Main Outcome Measures: Helicobacter pylori (H. pylori) infection determined by H. pylori stool antigen testing and/or urine $H$. pylori antibody test. Hypercalciuria was defined if the urinary excretion of calcium $>4 \mathrm{mg} / \mathrm{kg}$.

Results: Of the total 100 cases presenting idiopathic urolithiasis, 67 participants (67.0\%) were positive for $H$. pylori; and of the 50 controls, only 9 participants (18.0\%) were positive for $\mathrm{H}$. pylori. Statistical analysis revealed a highly significant difference between the two groups, where odds ratio $(\mathrm{OR})=9.2492,95 \% \mathrm{CI}=4.0200$ to $21.2801, \mathrm{Z}$ statistic $=5.233$, and $\mathrm{P}$ value $<0.0001$. Moreover, no statistically significant $(P$ value $>0.05)$ differences between the two groups in all laboratory parameters were observed, except for hypercalciuria where, a statistically significant $(P$ value $=0.0002)$ difference was evident between the case and control groups.

Conclusion: $H$. pylori infection was associated with the development of idiopathic hypercalciuric urinary stones and $H$. pylori may represent one of its etiological factors.

Keywords: H. pylori; Urolithiasis; Hypercalciuria; Ureases

\section{Introduction}

Renal stones in developing countries have different prevalence and etiology from those observed in industrialized countries. Furthermore, idiopathic urolithiasis in the upper urinary tract represents the most common type of urinary calculi [1]. Urolithiasis is common in many parts of the world. Crystalluria, the excretion of crystals in urine, is a marker of transient supersaturation of urine present both under pathological conditions and also under some normal physiological ones. Renal stones are polycrystalline aggregates which are often associated with crystalluria and urinary tract infection. In some instances, crystalluria is associated with pathological conditions such as urolithiasis [2]. Crystals of less than $5 \mathrm{~mm}$ diameter pass out freely through the urinary tract, but the crystals of more than $5 \mathrm{~mm}$ diameter get obstructed in the passage leading to calculus formation. In this context, urinary tract infections have a dual role where; (a) some urea-splitting organisms, such as Proteus mirabilis, may promote precipitation of phosphates and oxalates in alkaline media, and (b) the sharp edges of oxalate calculi damage the urinary tract epithelium and encourage the growth of organisms by forming the nidus to the infectious agents [3]. Persistent urinary tract infection with urea splitting or non-splitting bacteria may be the initial factors in the synthesis of renal stones and a distinct association between urinary stones and urinary tract infection has been previously reported [4]. It is currently proved that crystallization process begins in the distal ducts of the kidney by adhesion of calcium and oxalate to the epithelial surfaces of the tubule cells. Then, the calcium 
oxalate crystals become detached, with some incorporated organic materials forming a microlith. Subsequently, the microliths pass through the collecting tubules more slowly than calcium oxalate in simple physiological solution, aggregating until they reach the pelvicalycial system, where they grow into stones and pass down the ureters [5]. Patients with unexplained hypercalciuria have been labeled as having idiopathic hypercalciuria which accounts for $30-40 \%$ of calcium oxalate stone formers, and those without hypercalciuria as having idiopathic stone disease [6].

H. pylori is more frequently found in gastric antrum than in duodenal biopsies. Even though $H$. pylori can be generally cultured from gastric antrum, it can be cultured from gastric juice in only $15 \%$ of patients with $H$. pylori and from less than $50 \%$ of esophageal biopsies in esophagitis patients [7]. Thus, it is always important to obtain antral and corpus biopsies from persons recently treated with acid-suppressive drugs to assess the therapeutic outcomes, whereas duodenal and esophageal biopsies, gastric juice, and detection of stool antigens are useful for diagnosis of $H$. pylori infection [8]. Furthermore, H. pylori could be cultured from extragastric specimens such as ectopic mucosa in Meckel's diverticulum, esophagus, rectum, urinary bladder, dental plaque, and feces [7]. Recently, $H$. pylori has also been detected by PCR in specimens from the gall bladder and liver [9]. Ureases, nickelcontaining metalloenzymes of high molecular weight, are found in some pathogenic bacteria and fungi and they may represent a virulence factor in some pathogens such as $H$. pylori [10]. In contrast to the other bacterial ureases, $H$. pylori urease possesses both cytoplasmic activity as well as extracellular activity within the host cells [5]. The current study addresses the potential association between $H$. pylori infection and idiopathic hypercalciuric urolithiasis in pediatric patients.

\section{Materials \& Methods}

\section{Participating patients}

Between March 2013 and June 2014, 150 pediatric patients were enrolled in this study from cases attending the outpatient clinic and from the admitted patients at Al-Azhar University Hospitals, Cairo and Dommiat, in Egypt as well as at Noor-Khan General Hospital of Hafer Al-Batin, Saudi Arabia. This study was approved by the Bioethics Commissions of these Hospitals.

\section{Inclusion \& Exclusion criteria}

Male and female patients, aged below 18 years (to broaden the spectral range of cases), with symptoms of renal colic; abdominal pain with burning micturition, gross or defined microscopic hematuria, [11] normal renal function (creatinine clearance $\geq 60 \mathrm{ml} /$ $\mathrm{min}$ ), absence of proteinuria, and negative uro-culture at the moment of evaluation represent the inclusion criteria of this study. On the other hand, pregnant women, patients with any intestinal pathology (chronic diarrhea or Crohn's Disease), calcium metabolic disorders (hyperparathyroidism, hyperthyroidism), osteoporosis, or patients who used corticoids or antibiotics (at least within the last 2 weeks), and those on long term antibiotic therapy, particularly for $H$. pylori infection, were excluded from this study. The metabolic investigation protocol consisted of non-consecutive collection of two samples of 24-hour urine for calcium, sodium, uric acid, citrate, oxalate, magnesium and urinary volume. Serum levels of calcium, phosphorus, uric acid, sodium and parathormone were evaluated for all patients as described previously [12]. X-ray on kidneys, ureters, and bladder (KUB; for detection of radio opaque calculi) as well as ultrasonographic scan on abdomen and pelvis were carried out for some selected cases. Cases were distributed into two groups according to the presence of urolithiasis; group (1) cases (urolithiasis-positive) and group (2) control (urolithiasis-negative); both groups were matched for age, sex, race, and other sociodemographic characteristics. Idiopathic hypercalciuria ( $\mathrm{IH}$ ) was reported if the urinary excretion of calcium $>4 \mathrm{mg} / \mathrm{kg}$ [1]. The urine samples were analyzed and crystals were examined under phase contrast microscopy equipped with polarized filters for clear demonstration of crystals as described previously [3].

\section{Detection of $H$. pylori infection}

A commercial kit, ImmunoCard STAT Hp SA (Meridian Bioscience, Europe) has been utilized to detect $H$. pylori antigen in stool. It is a rapid, simple, cheap, reliable, and non-invasive technique to detect current $H$. pylori infection and can be used in monitoring of H. pylori eradication after antimicrobials therapy [13]. A commercial office-based kit (RAPIRUN test; Otsuka Pharmaceutical Co., Ltd., Tokyo, Japan) utilizing immuno-chromatographic technique was employed to examine urine samples for $H$. pylori antibody. This urine-based test is a fast, inexpensive, reliable and easy-to-use tool for the diagnosis of $H$. pylori infection [14,15].

\section{Statistical analysis}

Chi square test and T test were performed to compare the groups by demographic variables and baseline outcome measures.

\section{Results}

Among the 150 pediatric patients, there was homogeneous distribution in both groups (urolithiasis-positive and urolithiasisnegative) regarding to mean age, weight, height, and Body Mass Index (BMI), which was calculated and classified according to World Health Organization (WHO) [16]. It is noteworthy that the geographic distributions of eligible participating children add 
more strength to the design of the current study. The mean age was $12.9 \pm 3.8$ years. Age distribution showed 20 (13.3\%) in the age group $\leq 7$ year; $34(22.7 \%)$ in the age group $7-10$ years; $40(26.7 \%)$ in the age group 10-14 years; and $56(37.3 \%)$ in the age group 15-18 years (Table 1). Of the 100 patients with idiopathic urolithiasis, 67 patients $(67.0 \%)$ were $H$. pylori-positive; and of the 50 controls, only 9 participants $(18.0 \%)$ showed positive $H$. pylori tests. Statistical analysis showed that odds ratio $($ OR $)=9.2492,95 \%$ $\mathrm{CI}=4.0200$ to $21.2801, \mathrm{Z}$ statistics $=5.233$, and $P$ value $<0.0001$. Consequently, a statistically significant difference between the two groups was evident (Table 2). Descriptive data and baseline comparisons between the groups showed no significant initial differences between the tested groups except for hypercalciuria which revealed a statistically significant difference between the two groups, based on the statistical analysis of the data $[\mathrm{OR}=3.9464,95 \% \mathrm{CI}=1.9162-8.1277, \mathrm{Z}$ statistics $=3.724$, and $P$ value $=$ 0.0002] (Table 3).

\begin{tabular}{|c|c|c|}
\hline \multirow[b]{2}{*}{ Characteristics $^{\mathrm{a}}$} & \multicolumn{2}{|c|}{ Participants No. (\%) } \\
\hline & $\begin{array}{c}\text { Case } \\
(\text { Group1) } \\
(n=100)\end{array}$ & $\begin{array}{c}\text { Control } \\
\text { (Group 2) } \\
(n=50)\end{array}$ \\
\hline \multicolumn{3}{|l|}{ Age (year) } \\
\hline $5-10$ & $37(37.0 \%)$ & $17(34.0 \%)$ \\
\hline $10-18$ & $63(63.0 \%)$ & $33(66.0 \%)$ \\
\hline Weight (kg) & $34.14 \pm 7.12$ & $33.56 \pm 8.03$ \\
\hline Height (meter) & $1.34 \pm 0.9$ & $1.34 \pm 0.7$ \\
\hline BMI $\left(\mathrm{kg} / \mathrm{m}^{2}\right)$ & $26.78 \pm 4.71$ & $26.21 \pm 4.28$ \\
\hline \multicolumn{3}{|l|}{ Gender } \\
\hline Male & $60(60.0 \%)$ & $28(56.0 \%)$ \\
\hline Female & $40(40.0 \%)$ & $22(44.0 \%)$ \\
\hline \multicolumn{3}{|l|}{ Child race } \\
\hline Saudi Arabian & $33(33.0 \%)$ & $17(34.0 \%)$ \\
\hline Egyptian & $36(36.0 \%)$ & $18(36.0 \%)$ \\
\hline Others & $31(31.0 \%)$ & $15(30.0 \%)$ \\
\hline \multicolumn{3}{|l|}{ Insurance } \\
\hline Medicad & $73(73.0 \%)$ & $37(74.0 \%)$ \\
\hline Private, cash & $27(27.0 \%)$ & $13(26.0 \%)$ \\
\hline \multicolumn{3}{|c|}{ Total annual outcome (US \$) } \\
\hline$<10000$ & $55(55.0 \%)$ & $27(54.0 \%)$ \\
\hline $10000-30000$ & $19(19.0 \%)$ & $10(20.0 \%)$ \\
\hline $3000-50000$ & $15(15.0 \%)$ & $07(14.0 \%)$ \\
\hline$>50000$ & $11(11.0 \%)$ & $06(12.0 \%)$ \\
\hline
\end{tabular}

aSocioeconomic status is based on parental occupation. Education was nearly balanced among participants' parents, particularly when considering the average level nature of the hospital community. BMI=Body Mass Index.

Table1: Demographic characteristics of 150 participants including case group (urolithiasispositive) and control group (urolithiasis-negative).

\begin{tabular}{|c|c|c|}
\hline Helicobacter pylori infection & Case (Group 1) & Control (Group 2) \\
\hline Positive & $67(67.0 \%)$ & $9(18.0 \%)$ \\
\hline Negative & $33(33.0 \%)$ & $41(82.0 \%)$ \\
\hline Total & $100(100 \%)$ & $50(100 \%)$ \\
\hline
\end{tabular}

N.B: Odds Ratio $(\mathrm{OR})=9.2492,95 \% \mathrm{CI}=4.0200$ to $21.2801, \mathrm{Z}$ statistic $=5.233, \mathrm{P}$ value $<0.0001$. Statistical analysis indicates a significant difference between the two groups.

Table 2: Distribution of Helicobacter pylori infection among pediatric patients with positive (Group 1) and negative (Group 2) idiopathic urolithiasis. 


\begin{tabular}{|l|c|c|}
\hline \multicolumn{1}{|c|}{ Abnormalities } & $\begin{array}{c}\text { Case (Group 1) } \\
\text { No. of patients (\%) }\end{array}$ & $\begin{array}{c}\text { Control (Group 2) } \\
\text { No. of patient (\%) }\end{array}$ \\
\hline Anemia $(\mathrm{Hgb}<10 \mathrm{gm})$ & $20(20 \%)$ & $9(18.0 \%)$ \\
\hline Bun $>40 \mathrm{mg} / \mathrm{dl}$ & $1(1.0 \%)$ & $0(0.0 \%)$ \\
\hline Hyponatremia $(\mathrm{Na}<130 \mathrm{mEq} / \mathrm{L})$ & $2(2.0 \%)$ & $1(2.0 \%)$ \\
\hline Hyperkalemia $(\mathrm{K}>5.5 \mathrm{mEq} / \mathrm{L})$ & $4(4.0 \%)$ & $1(2.0 \%)$ \\
\hline Hypokalemia $(\mathrm{K}<3.5 \mathrm{mEq} / \mathrm{L})$ & $2(2.0 \%)$ & $1(2.0 \%)$ \\
\hline Hypocalcemia $(\mathrm{Ca}<8.5 \mathrm{mg} / \mathrm{dl})$ & $4(4.0 \%)$ & $1(2.0 \%)$ \\
\hline Hyperurecemia $(\mathrm{Ua}>6 \mathrm{mg} / \mathrm{dl})$ & $4(4.0 \%)$ & $7(14.0 \%)$ \\
\hline Hypocarbia $(\mathrm{HCO}<20 \mathrm{mEq} / \mathrm{L})$ & $18(18.0 \%)$ & $7(14.0 \%)$ \\
\hline Acidemia $(\mathrm{pH}<7.35)$ & $17(17.0 \%)$ & $10(20.0 \%)$ \\
\hline Hyperphosphatemia $(\mathrm{P}>6.5 \mathrm{mg} / \mathrm{dl})$ & $24(24.0 \%)$ & $16(32.0 \%)$ \\
\hline Hypercalciuria & $65(65.0 \%)$ & $10(20.0 \%)$ \\
\hline Hyperoxaluria & $28(28.0 \%)$ & $9(18.0 \%)$ \\
\hline Hypocitraturia & $27(27.0 \%)$ & \\
\hline
\end{tabular}

N.B: No significant difference between the groups in all parameter except in hypercalciuria in which, Odds Ratio $(\mathrm{OR})=3.9464$. 95\% Confidence Interval $(\mathrm{CI})=1.9162-8.1277$. Z statistics $=3.724(P$ value $=0.0002)$.

Table 3: Abnormalities in laboratory tests observed in the studied pediatric patients including case (Urolithiasis-positive) and control (Urolithiasis-negative) groups.

\section{Discussion}

To our knowledge this study is the first to identify and uncover the role of $H$. pylori infection in the pathogenesis of idiopathic urolithiasis in pediatric patients. Urolithiasis showed increased prevalence worldwide as a result of the changes in dietary habits in the last few decades [17]. There is a prominent variation in the prevalence of idiopathic urolithiasis in different countries. The lowest prevalence of urolithiasis was reported in Japan (0.6\%) [18], whereas its prevalence was remarkably high in the USA (12-13\%) [19]. Hypercalciuria is the most common etiology of urolithiasis in children and adults [20]. Etiology of pediatric urolithiasis remains fundamentally unknown in the developing countries [21,22]. Some investigators revealed the coexistence of infection, anatomical abnormalities, and metabolic causes in up to $90 \%$ of the reported cases of urolithiasis [23]. This emphasizes the importance of the investigations that address the risk factors and that elucidate the etiology as well as pathogenesis of the stone diseases among pediatric patients, especially, in developing countries. Several studies have demonstrated an association between H. pylori infection and hepatobiliary disorders, including gall stone formation [24,25]. The postulated mechanism to explain the association between hepatobiliary colonization with urease-positive Helicobacter species and gallstone formation indicated that urease-positive Helicobacter species may induce the development of gall stones both directly via their urease activity and indirectly via the immune response to the pathogen [26]. The current study is innovative in investigating the impact of $H$. pylori infection on pediatric urolithiasis and renal stone formation.

Results of this study revealed that $H$. pylori infection is associated with the development of idiopathic hypercalciuric urinary stones and this may be attributed to one or more of $\mathrm{H}$. pylori-virulence factors such as urease. It has been proposed that kidney stone formation is a nanobacterial disease, analogous to peptic ulcer disease associated with $H$. pylori infection. Both diseases, kidney stone formation and peptic ulcer, are initiated by bacterial infections and subsequently endogenous and dietary factors may influence their progressions [27]. In addition to the previously established association between urinary tract infection (caused by non- $H$. pylori pathogens such as Proteus mirabilis) and urolithiasis, $H$. pylori in our study appeared prominently among case group and it has been positively diagnosed in almost $2 / 3$ of the pediatric cases. Interestingly, the findings herein could be contextualized with the implications of two previous studies that may seem apparently unrelated; (1) A randomized, double-blind placebocontrolled trial which demonstrated that oral cimetidine gives effective symptomatic relief in painful bladder disease [28], and (2) A case controlled study that reported a high prevalence of Helicobacter infection in patients with primary hyperparathyroidism which consequently leads to hypercalcemia [29]. Such studies may underlie the potential role of H. pylori in the etiology of various extra-gastrointestinal diseases. With respect to induction of calcium precipitation and hypercalciuria, our findings are consistent with other studies which reported that bacterial urease catalyzes the production of ammonia from urea. This renders the urine more alkaline, which favors precipitation of struvite (magnesium ammonium phosphate) and calcium phosphate [30-32].

The proposed mechanisms underlying the association between $H$. pylori infection and hypercalciuric urolithiasis may involve: (1) hypersensitivity of calcium-sensing receptors of the host gastric antral $\mathrm{G}$ cells resulting from $\mathrm{H}$. pylori infection with subsequent induction of antral G cell hyperfunction [33,34], (2) the unique characteristic of $H$. pylori urease enzyme which along with its cytoplasmic activity, has extracellular activity within the host cells [5]. Thus, the unique extracellular activity of the H. pylori urease 
could provide an easy access to any extragastric sites such as urinary tract routes. In the current study, to rule out a possible cross reactivity of the commercial kits for detection of $H$. pylori with other urease-producing bacteria causing urinary infection such as Proteus mirabilis, the specific $H$. pylori stool antigen test was essentially implemented. It is noteworthy that, another two studies failed to detect $H$. pylori DNA in interstitial cystitis $[35,36]$. Nevertheless, the small sample size of those studies and the consistent difference in pathogenesis between interstitial cystitis and hypercalciuric urolithiasis eliminate the possible contradiction between those reports and our study findings. By far, the most common types of kidney stones worldwide contain calcium in their compositions. For instance, calcium-containing stones represent about $80 \%$ of all cases; these typically contain calcium oxalate either alone or in combination with calcium phosphate. The formation of calcium phosphate stones is generally associated with particular conditions such as hyperparathyroidism and renal tubular acidosis. Furthermore, about 10-15\% of urinary calculi are composed of struvite (ammonium magnesium phosphate). Struvite stones (also known as infection stones, or urease stones), and they mostly develop in the presence of infection by some urea-splitting bacteria. On the other hand, uric acid stones represent only $5-10 \%$ of all urinary tract stones [37]. Taken together the previous data, we postulate that $H$. pylori infection may induce approximately $90 \%$ of renal stones either directly by providing calcium and hypercalciuria, or indirectly through production of urease enzyme. It is well known that gastric $H$. pylori urease decomposes urea into carbon dioxide and ammonia [26]. The authors postulate that ammonia may be absorbed through the blood, reaching the urinary tract, and consequently induces urolithiasis. Such postulated mechanism of $H$. pylori urease-mediated urolithiasis requires further confirmation through utilizing radio-labeled nitrogen in the future studies.

The findings of our study may not obviate the need for continued screening of Helicobacter infection and its correlation with other idiopathic urinary tract diseases. Future sophisticated studies are also required to clarify the nature and the relative contribution of the various virulence factors associated with $H$. pylori, particularly their roles in evading the body immune surveillance, and hypercalciuric urolithiasis as well as the subsequent link between $H$. pylori eradication and recovery from different idiopathic urolithiasis.

\section{Conclusion}

The results of this study revealed that $H$. pylori infection was associated with the development of idiopathic hypercalciuric urinary stones and $H$. pylori may represent one of its etiological factors.

\section{References}

1. Alaya A, Sakly R, Nouri A, Najjar MF, Belgith M, et al. (2013) Idiopathic urolithiasis in Tunisian children: a report of 134 cases. Saudi J Kidney Dis Transpl 24: $1055-61$.

2. Fogazzi GB (1996) Crystalluria: a neglected aspect of urinary sediment analysis. Nephrol Dial Transplant 11: 379-87.

3. Madhavi S, Prathyusha C, Rajender S (2012) Relationship between crystalluria and urinary calculi and associated urinary tract infection. J Microbiol Biotech Res 2: 351-6.

4. Zanetti G, Paparella S, Trinchieri A, Prezioso D, Rocco F, et al. (2008) Infections and urolithiasis: current clinical evidence in prophylaxis and antibiotic therapy. Arch Ital Urol Androl 80: 5-12.

5. Wesson JA, Worcester EM, Wiessner JH, Mandel NS, Kleinman JG (1998) Control of calcium oxalate crystal structure and cell adherence by urinary macromolecules. Kidney Int 53: 952-7.

6. Mayerson M (2003) Human genetic variation and disease. Lancet 362: 259-60.

7. Andersen LP, Wadstrom T (2001) Basic Bacteriology and Culture (Chapter 4) Source Helicobacter pylori: Physiology and Genetics, Washington (DC): ASM Press, USA.

8. Westblom TU, Phadnis S, Yang P, Czinn SJ (1993) Diagnosis of Helicobacter pylori infection by means of a polymerase chain reaction assay for gastric juice aspirates. Clin Infect Dis 16: 367-71.

9. Nilsson HO, Taneera J, Castedal M, Glatz E, Olsson R, et al. (2000) Identification of Helicobacter pylori and other Helicobacter species by PCR, hybridization, and partial DNA sequencing in human liver samples from patients with primary sclerosing cholangitis or primary biliary cirrhosis. J Clin Microbiol 38: 1072-6.

10. Yu XD, Xie JH, Wang YH, Li YC, Mo ZZ, et al. (2014) Selective antibacterial activity of Patchouli alcohol against Helicobacter pylori based on inhibition of urease. Phytother Res. doi: 10.1002/ptr.5227.

11. Mohammadjafari H, Barzin M, Salehifar E, Kord MK, Aalaee A, et al. (2014) Etiologic and Epidemiologic pattern of urolithiasis in North Iran; Review of 10year findings. Iran J of Pediat 24: 69-74.

12. Damasio PC, Amaro CR, Berto SJ, Cunha NB, Pichutte AC, et al. (2010) Urinary lithiasis and idiopathic hypercalciuria: the importance of dietary intake evaluation. Int Braz J Urol 36: 557-62.

13. Wu IC, Ke HL, Lo YC, Yang YC, Chuang CH, et al. (2003) Evaluation of a newly developed office-based stool test for detecting Helicobacter pylori: an extensive pilot study. Hepatogastroenterology 50: 1761-5.

14. Kato S, Tachikawa T, Ozawa K, Konno M, Okuda M, et al. (2001) Urine-based enzyme-linked immunosorbent assay for the detection of Helicobacter pylori infection in children. Pediatrics 107: E87.

15. Quach DT, Hiyama T, Shimamoto F, Le QD, Ho LX, et al. (2014) Value of a new stick-type rapid urine test for the diagnosis of Helicobacter pylori infection in the Vietnamese population. World J Gastroenterol 20: 5087-91.

16. World Health Organization (2008) Obesity: preventing and managing the global epidemic. Report of a WHO Consultation. WHO Technical Report Series, Geneva 894.

17. Ammenti A, Neri E, Agistri R, Beseghi U, Bacchini E (2006) Idiopathic hypercalciuria in infants with renal stones. Pediatr Nephrol 21: 1901-3. 
18. Kaneko K, Tsuchiya K, Kawamura R, Ohtomo Y, Shimizu T, et al. (2002) Low prevalence of hypercalciuria in Japanese children. Nephron 91(3): 439-43.

19. O’Brien KO, Abrams SA, Stuff JE, Liang LK, Welch TR (1996) Variables related to urinary calcium excretion in young girls. J Pediatr Gastroenterol Nutr 23: $8-12$.

20. Kingwatanakul P, Alon US (1999) Hypercalciuria and urolithiasis in childhood Pediatric nephrology. Amsterdam Harwood Academic Press, United Kingdom. 21. Hesse A, Tiselius GH, Siener R, Hoppe B (2002) Urinary Stones: Diagnosis, treatment and prevention of recurrence (2 ${ }^{\text {nd }}$ edn) Karger Publishers, London. 22. Sarkissian A, Babloyan A, Arikyants N, Hesse A, Blau N, et al. (2001) Pediatric urolithiasis in Armenia: a study of 198 patients observed from 1991 to 1999. Pediatr Nephrol 16: 728-32.

23. Milliner DS, Murphy ME (1993) Urolithiasis in pediatric patients. Mayo Clin Proc 68: 241-8.

24. Farshad Sh, Alborzi A, Malek Hosseini SA, Oboodi B, Rasouli M, et al. (2004) Identification of Helicobacter pylori DNA in Iranian patients with gallstones. Epidemiol Infect 132: 1185-9.

25. Tiwari SK, Khan AA, Ibrahim M, Habeeb MA, Habibullah CM (2006) Helicobacter pylori and other Helicobacter species DNA in human bile samples from patients with various hepato-biliary diseases. World J Gastroenterol 12: 2181-6.

26. Belzer C, Kusters JG, Kuipers EJ, van Vliet AH (2006) Urease induced calcium precipitation by Helicobacter species may initiate gallstone formation. Gut 55: 1678-9.

27. Ciftçioglu N, Björklund M, Kuorikoski K, Bergström K, Kajander EO (1999) Nanobacteria: an infectious cause for kidney stone formation. Kidney Int 56: 1893-8.

28. Haq A, Donaldson PJ, Parry JR (2001) Oral cimetidine gives effective symptom relief in painful bladder disease: a prospective, randomized, double-blind placebo-controlled trial. BJU Int 88: 444-5.

29. Dökmetaş HS, Türkay C, Aydin C, Arici S (2001) Prevalence of Helicobacter pylori in patients with primary hyperparathyroidism. J Bone Miner Metab 19: 373-7.

30. Kristensen C, Parks JH, Lindheimer M, Coe FL (1987) Reduced glomerular filtration rate and hypercalciuria in primary struvite nephrolithiasis. Kidney Int 32: 749-53.

31. Tasian GE, Copelovitch L (2014) Evaluation and medical management of kidney stones in children. J Urol. doi: 10.1016/j.juro.2014.04.108.

32. Edin-Liljegren A, Grenabo L, Hedelin H, Jonsson O, Akerlund S, et al. (1996) Concrement formation and urease-induced crystallization in urine from patients with continent ileal reservoirs. Br J Urol 78: 57-63.

33. Declich P, Belloni J, Tavani E, Omazzi B, Bellone S, et al. (2014) The morphological and immunohistochemical spectrum of gastric biopsies of patients with absorptive hypercalciuria. BMJ Open Gastro 1:E000004. doi:10.1136/bmjgast-2014-000004.

34. Sokic-Milutinovic A, Todorovic V, Milosavljevic T, Micev M, Drndarevic N, et al. (2005) Gastrin and antral G cells in course of Helicobacter pylori eradication: six months follow up study. World J Gastroenterol 11: 4140-7.

35. Agarwal M, Dixon RA (2003) A study to detect Helicobacter pylori in fresh and archival specimens from patients with interstitial cystitis, using amplification methods. BJU Int 91: 814-6.

36. Haq A, Mattocks S, Wong L, Dasgupta P, Dawson C, et al. (2001) Incidence of Helicobacter pylori in patients with interstitial cystitis. Eur Urol 40: 652-4.

37. Moe OW (2006) Kidney stones: pathophysiology and medical management. Lancet 367: 333-44.

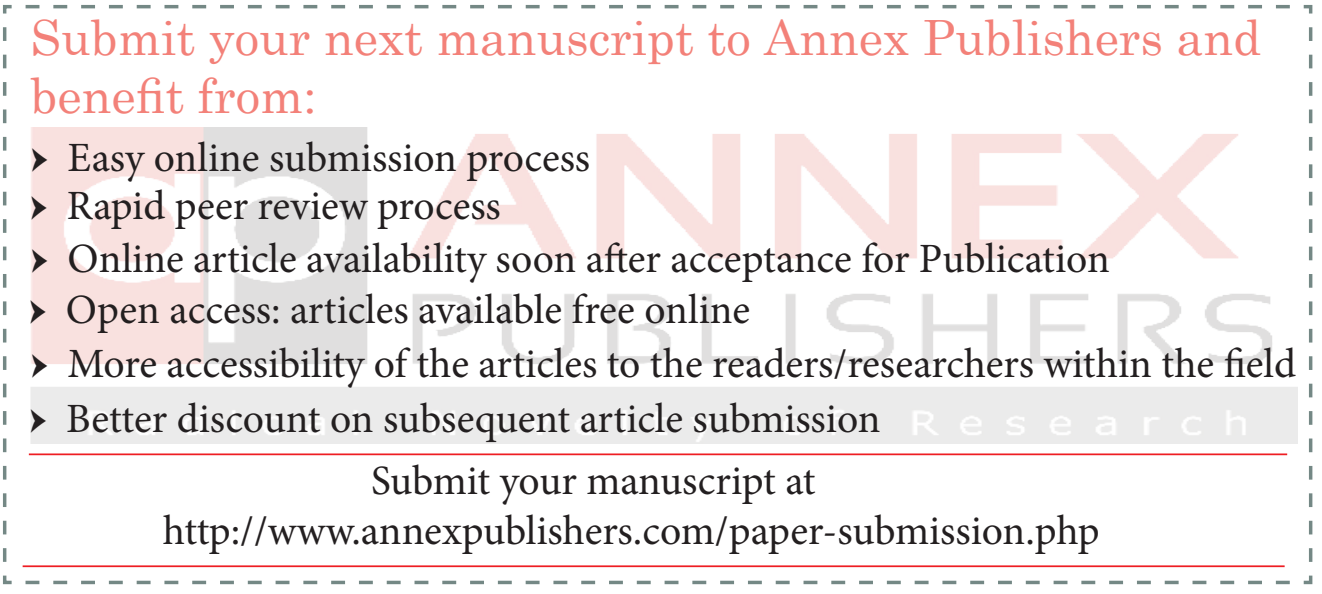

